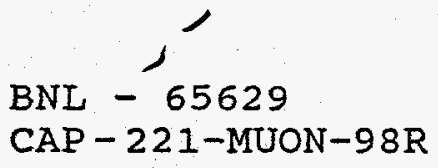

EXPERIMENT OF ELECTRICAL CONDUCTIVITY AT LOW TEMPERATURE
(PRELIMINARY MEASUREMENT) *

Yongxiang Zhao and Haipeng Wang

Department of Physics

Brookhaven National Laboratory

Upton, NY 11973

*This work was performed under the auspices of the U.S.

Department of Energy under Contract No. DE-ACO2-98CH10886.

July 1998
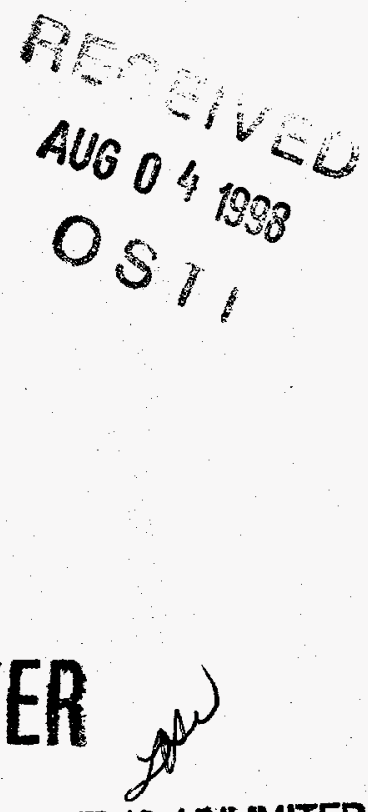

ABTHIBUTICN OF THS OOXUAET IS UNLMITED 


\section{DISCLAIMER}

This report was prepared as an account of work sponsored by an agency of the United States Government. Neither the United States Government nor any agency thereof, nor any of their employees, makes any warranty, express or implied, or assumes any legal liability or responsibility for the accuracy, completeness, or usefulness of any information, apparatus, product, or process disclosed, or represents that its use would not infringe privately owned rights. Reference herein to any specific commercial product, process, or service by trade name, trademark, manufacturer, or otherwise does not necessarily constitute or imply its endorsement, recommendation, or favoring by the United States Government or any agency thereof. The views and opinions of authors expressed herein do not necessarily state or reflect those of the United States Government or any agency thereof. 


\section{DISCLAIMER}

Portions of this document may be illegible electronic image products. Images are produced from the best available original document. 


\title{
EXPERIMENT OF ELECTRICAL CONDUCTIVITY AT LOW TEMPERATURE (PRELIMINARY MEASUREMENT)
}

\author{
Yongxiang Zhao, Haipeng Wang \\ Physics Department, Brookhaven National Laboratory, Upton, NY11973
}

\begin{abstract}
The results of the preliminary measurement on the electrical conductivity of copper at liquid nitrogen temperature were summarized. Addressed also are the data fitting method and the linear expansion of copper.
\end{abstract}

\section{INTRODUCTION}

A muon collider needs very large amount of RF power, how to reduce the RF power consumption is of major concern. Thus the application of liquid nitrogen cooling has been proposed [1]. However, it is known that the electrical conductivity depends on many factors and the data from different sources vary in a wide range, especially the data of conductivity of beryllium has no demonstration in a real application. Therefore it is important to know the conductivity of materials, which are commercially available, and at a specified frequency.

An experimental setup was designed and made. The preliminary measurement was done with some useful data collected. In addition, a fitting method was developed. It shows that this simple measurement has a good match with the theoretical prediction.

\section{EXPERIMENT SETUP}

Fig. 1 shows the layout of the setup. Fig. 2 is its photo. The cavity being tested is made of ETP copper. It is simply a pill box type, operating at TM010 mode. The top and bottom flanges are bolted on the cylinder wall, which will cause a certain amount of contact loss.

The RF parameter measurement was done by a network analyzer. The connection between the network analyzer and the cavity has to pass through two SMA type vacuum feedthroughs, which are mounted on the top cover of the cryogenic tank. So there are inevitably two other pieces of cable inside the cryostat to connect to the cavity, that makes some difficulties for the RF calibration, and thus measuring scattering parameter $S_{12}$ was preferred rather than $S_{11}$. That's why we chose the two-coupler option.

The cavity has four holes for inserting the RF couplers, which are loops rather than probes because all their locations are at high magnetic field areas. Two of them are on sidewall of the cylinder, for testing TM010 mode. Other two are on the top flange for testing the tape resonator in the next experiment. 


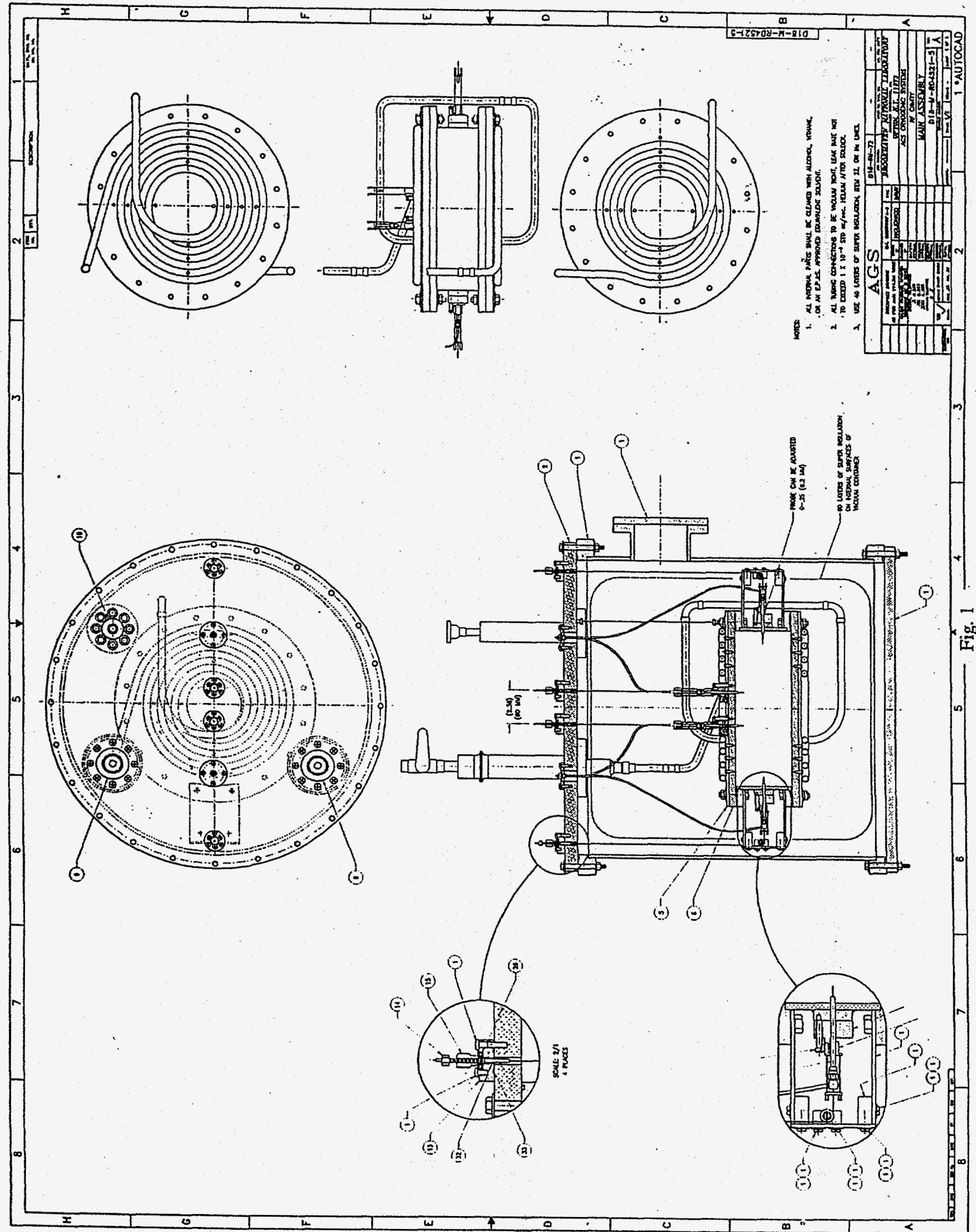


The coupling loop is made of semi-rigid cable. Each time only two of them are in use. Each coupler also has a holder, which is tied with a string, of which another end is tied on a mechanical feedthrough, so that the coupler can be in and out through the hole to adjust the coupling.

Both top and bottom plates are attached via screws with other two separate plates where cooling pipes are soldered on (see Fig.1). Using separate cooling plates has more flexibility in considering the case of that the bottom plate is replaced by another plate coated by sputtering beryllium. The cylinder has no cooling pipe but it was demonstrated that the thermal conduction is pretty good between cylinder and plates. The pipes also have a few thread connectors to make the assembly flexible.

There are four thermal sensors to monitor the temperatures. They are mounted on the top plate, the side of cylinder, the bottom plate

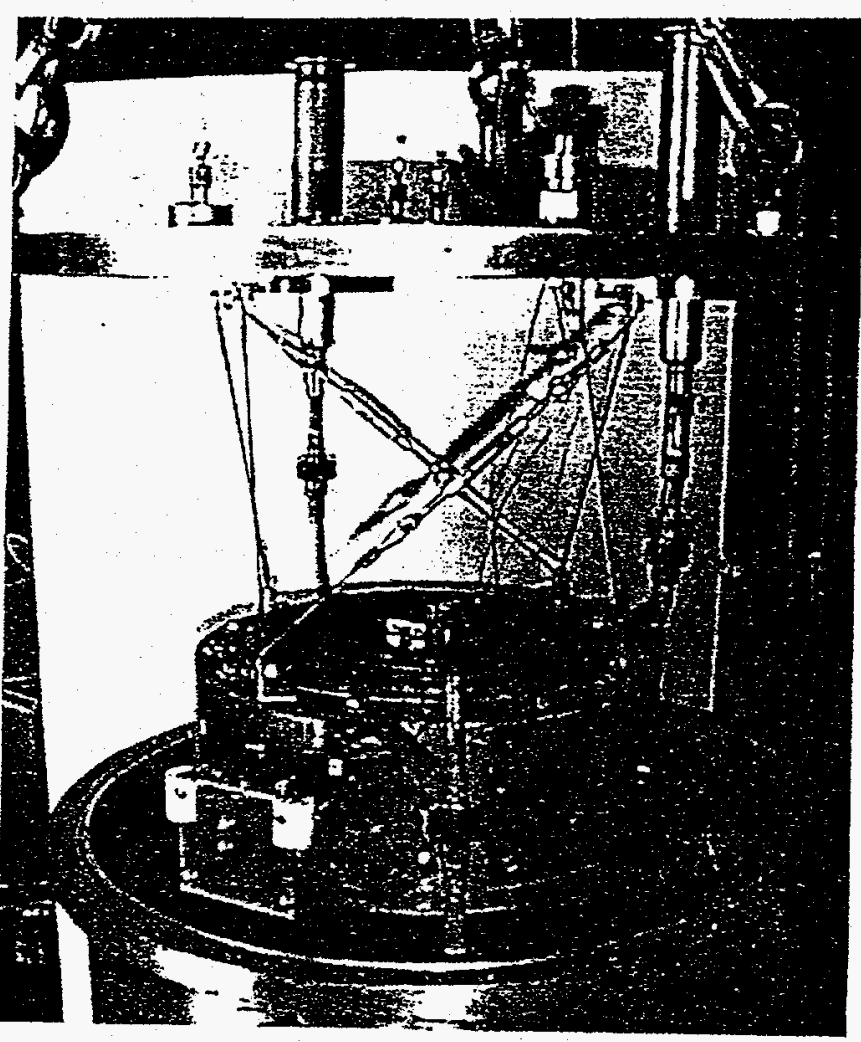

Fig.2 The test set up and the cooling pipe at the output side respectively. Except the last one, the temperature differences between other three sensors are always within $2^{\circ} \mathrm{C}$ in all measurements.

\section{TEST PROCEDURE}

At first, tested the quality factor $Q$ at room temperature and then cooled down the whole assembly to the liquid nitrogen temperature and tested again. The temperature of the cavity was $81 \mathrm{~K}$, which was a little higher than the liquid nitrogen temperature at one atmosphere, because the liquid nitrogen in the cooling manifold was at a higher pressure. Then let it warm up itself. Meanwhile the coupler was kept at its most weak coupling, i.e. drawing out to its farthest possible position from the coupling hole, and then tested its $Q$ at different temperature. Only at a few special temperatures we've tested the $Q$ with variable coupling. The temperature warm up was too slow initially, only about 30 degrees centigrade over one night. We first tried to use hair dryer to blow hot air into the cooling pipe but found little effect because of too low wind pressure. Later on we tried to blow compressed air of room temperature and succeed.

\section{THE Q VALUE MEASUREMENT}

The major RF instrument was the network analyzer. At the beginning we used HP8510A along with a sweeper of HP8350B, test set HP8511A. It was found the 
frequency resolution was too poor at $800 \mathrm{MHz}$ range, so that the data were unstable and unreliable. After replacing the whole set by . HP8753D, the stability and results were much better.

Fig. 3 summarizes the measured data of $Q$ value at different temperature. The round spots are the $Q$ s calculated by the measured $3 \mathrm{~dB}$ bandwidths. In principle the unloaded $\mathrm{Q}$

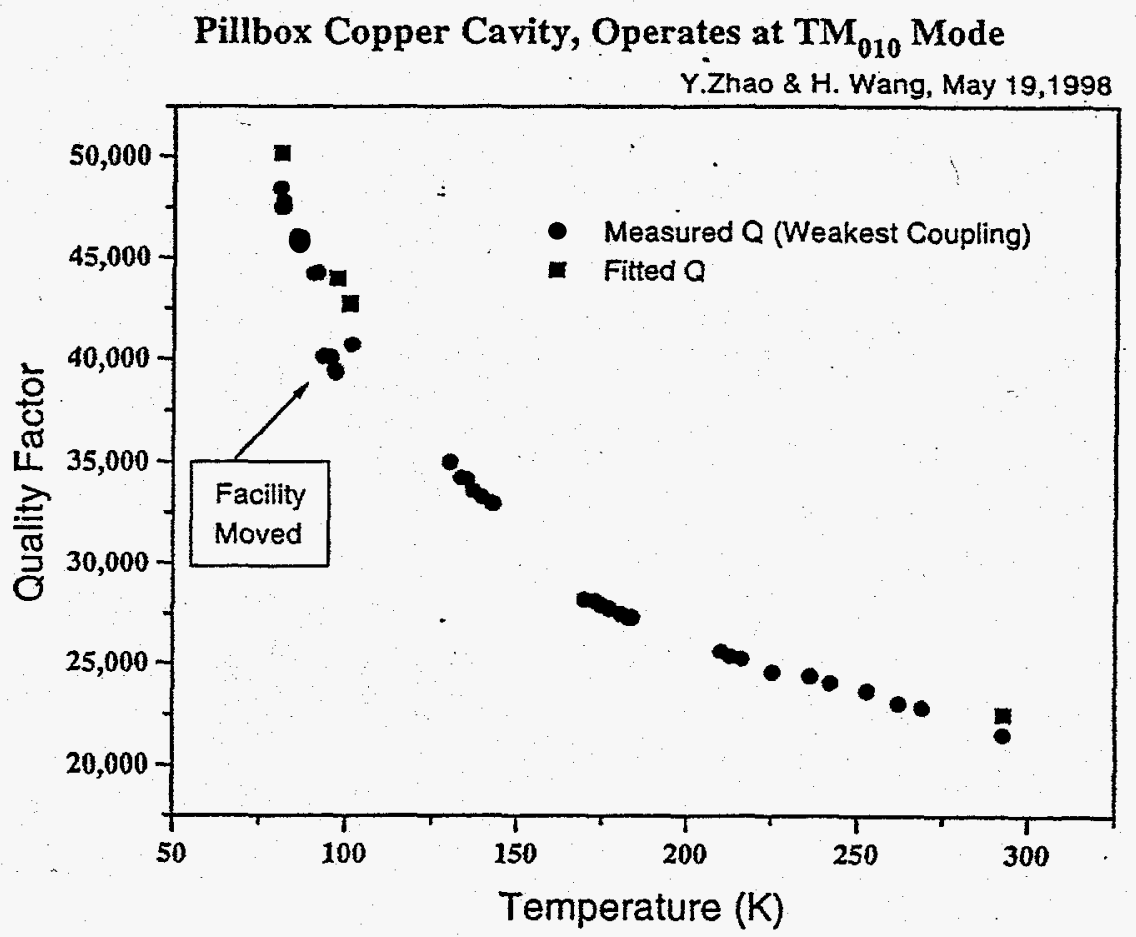

Fig.3 The $Q$ at different temperature

should be at a condition that the coupling is infinitive weak. However, the weakest realizable coupling seemed not adequate.

Fig. 4 shows the measured $3 \mathrm{~dB}$-bandwidth $\Delta \mathrm{f}$ dependence with the relative coupling. The horizontal axis is the measured reference value of $S_{12}$ in $\mathrm{dB}$. The real coupling parameter $\beta$ is unknown. A fitting function was figured out, addressed in the next section. From the fitting we found the limitation at infinitive weak coupling and then one can calculate the unloaded $Q$. The square spots on the figure show those fitting data.

\section{FITTING METHOD}

For a test cavity with two couplers we have:

$$
\begin{aligned}
& Q_{0}=Q_{L}\left(1+\beta_{1}+\beta_{2}\right) \\
& T=\frac{2 \sqrt{\beta_{1} \beta_{2}}}{1+\beta_{1}+\beta_{2}}
\end{aligned}
$$



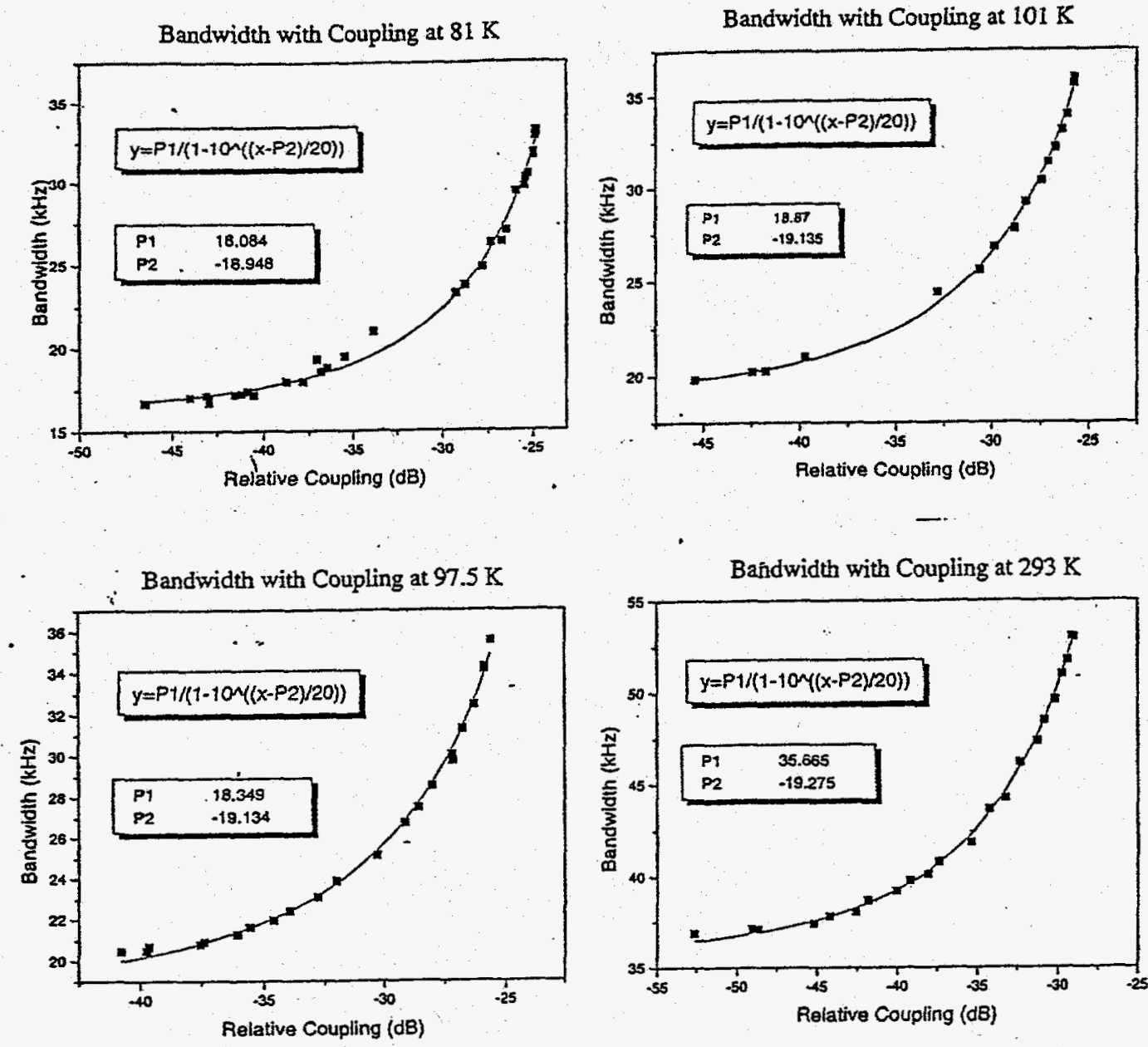

Fig. 4 Bandwidth-Coupling dependence and its fitting function

where $Q_{0}$ and $Q_{L}$ are unloaded and loaded $Q$ respectively, $\beta_{l}$ and $\beta_{2}$ are the coupling coefficient of two couplers, $T$ is the transfer function.

Assuming $\beta_{1} \approx \beta_{2}$, or $\beta=\sqrt{\beta_{1} \beta_{2}} \approx \frac{1}{2}\left(\beta_{1}+\beta_{2}\right)$, then

$$
\begin{aligned}
& Q_{0}=Q_{L}(1+2 \beta) \\
& T=\frac{2 \beta}{1+2 \beta}
\end{aligned}
$$

The parameters being measured are frequency $f_{0}, 3 \mathrm{~dB}$ bandwidth $\Delta f$ and $S_{12}$, and they have following relationship:

$$
\begin{aligned}
Q_{0} & =f_{0} / \Delta f_{0} \\
Q_{L} & =f_{0} / \Delta f \\
S_{I 2} & =20 \log T+C
\end{aligned}
$$

Note that the tested $S_{12}$ is relative value in $\mathrm{dB}$ with an arbitrary constant. Then we get the fitting function: 


$$
S_{12}=C+20 \log \left(1-\frac{\Delta f_{0}}{\Delta f}\right)
$$

or

$$
\Delta f=\Delta f_{0} /\left[1-10^{\left(\frac{s_{12}-c}{20}\right)}\right]
$$

Thus the following user's function was applied at the code ORIGIN:

$$
Y=P 1 /\left(1-10^{\wedge}((X-P 2) / 20)\right)
$$

Where $Y=\Delta f, X=S 12$. The fitting parameter, $P 1=\Delta f_{0}$, was what we searched for, it corresponds to the limit of infinitive weak coupling.

Therefore the unloaded $Q$ is:

$$
Q_{0}=f_{0} / P 1
$$

The fitting results are shown in Fig. 3 with the square spots

\section{TEST RESULTS}

The following table shows the summarized data:

Copper at room temperature

$\begin{array}{ll}\text { Theoretic Q: } & 25227 \\ \text { Measured Q: } & 22550 \\ \text { Ratio: } & 89 \%\end{array}$

$Q$ as a function of temperature

\begin{tabular}{|l|l|l|l|c|}
\hline $\begin{array}{l}\text { Temperature } \\
\mathrm{T}(\mathrm{K})\end{array}$ & $\begin{array}{l}\text { Frequency } \\
\mathrm{f}_{0}(\mathrm{MHz})\end{array}$ & $\begin{array}{l}\text { Bandwidth } \\
\Delta \mathrm{f}(\mathrm{kHz})\end{array}$ & Q value & QEF \\
\hline 81 & 806.632 & 16.084 & 50150 & 2.224 \\
\hline 97.5 & 806.506 & 18.349 & 43950 & 1.949 \\
\hline 101 & 806.480 & 18.87 & 42740 & 1.895 \\
\hline 293 & 804.201 & 35.665 & 22550 & 1 \\
\hline
\end{tabular}

Theoretically, Q enhancement factor QEF is about 2.8 at $80 \mathrm{~K}$. The difference between the measured and theoretical one may be due to (a) Contact Loss (major cause); (b) Unperfected surface smoothness; (c) Anomalous skin effect (unlikely):

\section{LINEAR EXPANSION OF COPPER}

It is found that the frequency data were much precise than that of $Q$ values. Fig. 5 shows the tested curve of frequencies-temperature dependence. It is very smooth. Since the resonance wavelength is a linear function of the cavity dimension, the variation of 
Pillbox Copper Cavity, Operates at $\mathrm{TM}_{010}$ Mode

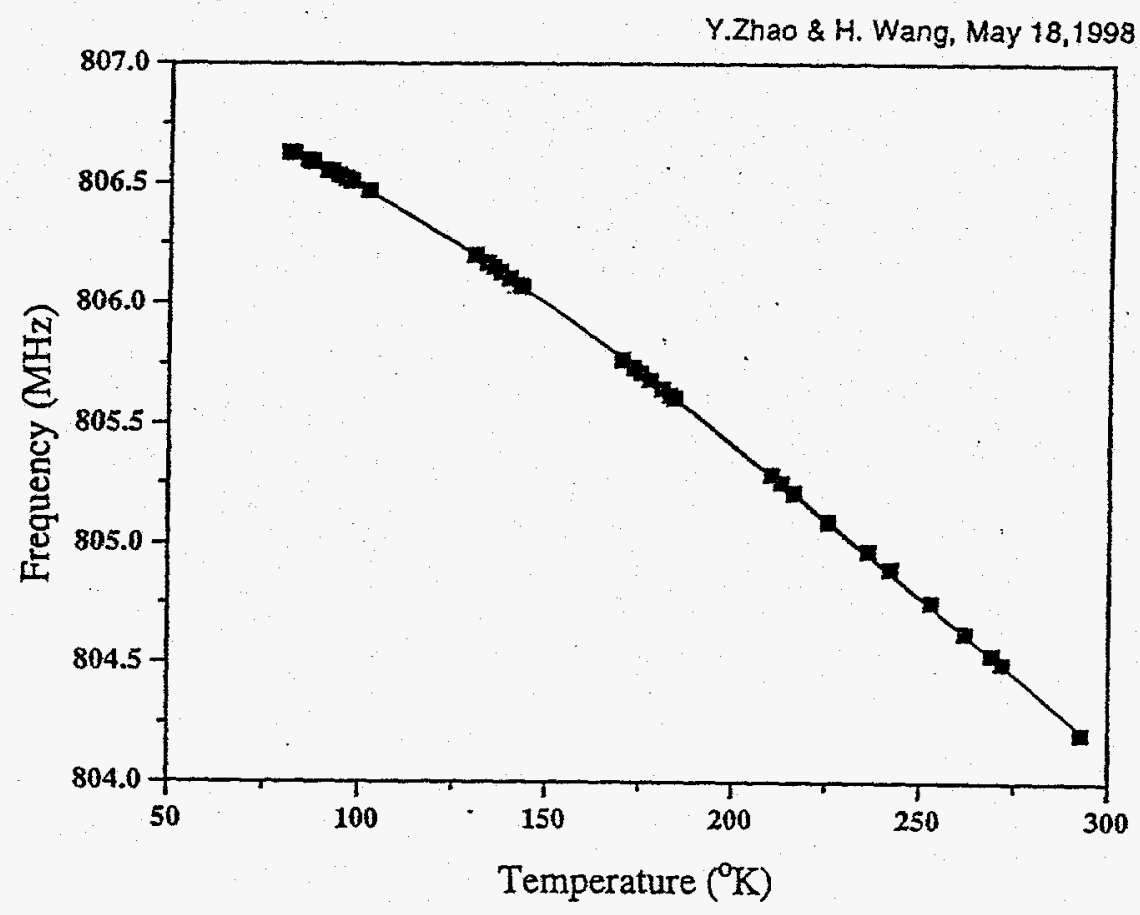

Fig. 5 The frequency variation with the temperature

The Expansion of Copper Indicated by Frequency Change

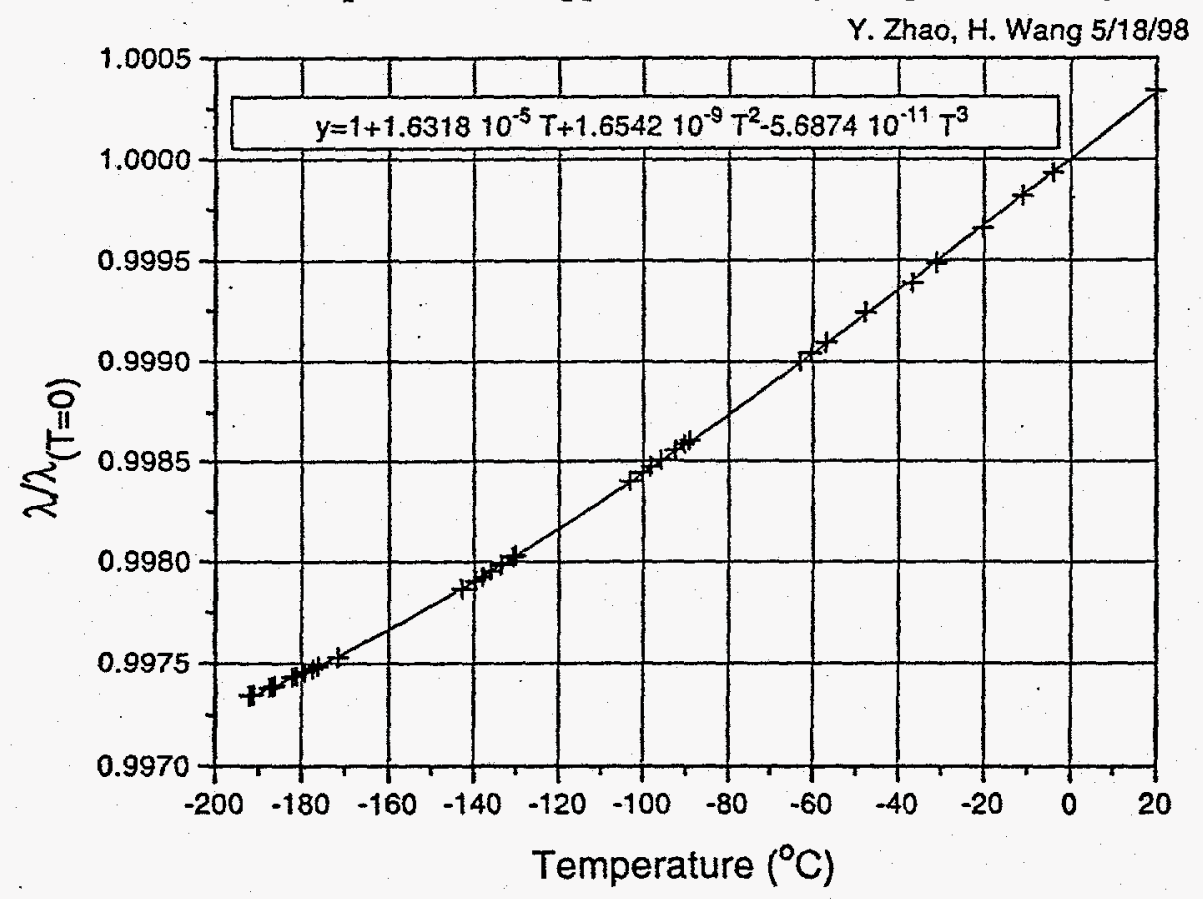

Fig. 6 The normalized wavelength or the linear expansion of copper with temperature 
frequency with temperature will be an indication of the size change of the cavity with temperature. Fig. 6 shows the curve of the normalized wavelength, it is also the thermal expansion of the copper.

We have also tested the TE011 mode to check if its $\mathrm{Q}$ is more close to the theoretical prediction due to little contact loss. However, the TE011 mode has mode degeneration with TM111 mode, which caused much error on the $Q$ measurement.

\section{SUMMARY}

- The test setup works ok. The warm up process was too slow. Using compressed air to speed up warming was a good practice. The coupler mechanical repeatability needs improvement.

- A data fitting method with a simple measurement was developed and successful.

- The tested $Q$ value is $89 \%$ of theoretical expectation. Nevertheless it seems to be a good reference data in the real world.

- The $Q$ value increases rapidly when the temperature closes to $77 \mathrm{~K}$. What will be at liquid nitrogen temperature remains to be seen.

- The linear expansion function of copper was nicely determined by the frequency measurement. It is reasonably consistent with the data given in other sources.

- It turns out we may make use of the frequency as an indicator of temperature. Especially for the next step for the tape resonator where the temperature can not be measured directly by attaching a sensor on the tape.

- But, the expansion coefficient as a function of temperature obtained by the fitting is not recommended, because it strongly depends on the fitting function.

\section{ACKNOWLEDGEMENTS}

This work was supported by the US DOE under Contract No. DE-AC02-98CH10886. Also was encouraged and supported by all the members in CAP group. We are especially indebted to many colleagues Labwide who helped a lot in all respects to make this experiment realizable, among them are L. Jia, V. LoDestro, L. Addessi, L. Snydstrup, G. Miglionico, M. McNeill, T. Lelle, X. J. Wang and many others.

\section{REFERENCES}

[1] Y. Zhao "A normal conducting accelerator for a muon collider demonstration, machine", PAC 97, Vancouver, May 1997; 'Liquid nitrogen cooling for accelerator RF", Muon Collider Workshop, May 17-20, 1997 